\title{
DIFICULDADE DE NARRAR: A PROSA FICCIONAL DE SEVERO SARDUY
}

THE DIFFICULTY OF NARRATING:

\author{
THE PROSE FICTION OF SEVERO SARDUY
}

\section{Antonio Andrade}

Universidade Federal do Rio de Janeiro

Rio de Janeiro - RJ, Brasil

\begin{abstract}
Resumo
Neste artigo, analiso a obra ficcional de Severo Sarduy, indicando nela a produtividade da tensão entre linguagem, desejo e comunidade para se discutir, numa perspectiva oblíqua, o caráter político do discurso literário neobarroco na América Latina. Ao analisar os textos narrativos, busco problematizar a abordagem formalista do literário, evidenciando a relação entre literatura e experiência, reflexão metalinguística e debate sócio-histórico. No desdobramento desta discussão, enfatizo a percepção a respeito da "dificuldade de narrar", sinalizada e enformada por Sarduy de diferentes formas: processo discursivo que se liga à noção de crise de valores ideológicos e estéticos, experienciada por esse instigante escritor que atuou decisivamente no campo artístico e intelectual da segunda metade do século XX.
\end{abstract}

Palavras-chave: narrativa, neobarroco, política, experiência.

\section{Abstract}

In this article I analyze Severo Sarduy's fictional work, noting in it the fruitful tension between language, desire and community with the aims of discussing, from an oblique perspective, the political nature of neo-baroque literary discourse in Latin America. Through the analysis of Sarduy's narrative texts, I seek to question the formalistic approach to the literary, underscoring the relationship between literature and experience, metalinguistic reflection and socio-historical debate. In the unfolding of this discussion, I emphasize the perception of the "difficulty of narrating", which was signalled and shaped by Sarduy in various ways, thus demonstrating that his discursive process is linked to the notion of crisis of ideological and aesthetic values, as

\section{Resumen}

En este artículo, se analiza la obra ficcional de Severo Sarduy, señalando la productiva tensión entre lenguaje, deseo y comunidad con el fin de discutir, desde una perspectiva oblicua, el carácter político del discurso literario neobarroco en América Latina. Al analizar los textos narrativos, trato de poner en cuestión el enfoque formalista de lo literario, evidenciando la relación entre literatura y experiencia, reflexión metalingüística y debate socio-histórico. En el desarrollo de esta discusión, hago hincapié en la percepción de la "dificultad de narrar," construida y apuntada de varias maneras por Sarduy, demostrando así que su proceso discursivo se une a la noción de crisis de los valores ideológicos y estéticos, experimentada por este escritor 
experienced by this provocative writer who acted decisively in the artistic and intellectual fields in the second half of the twentieth century.

Keywords: narrative, neo-baroque, politics, experience. provocador que actuó, de manera decisiva, en el campo artístico e intelectual de la segunda mitad del siglo XX.

Palabras claves: narrativa, neobarroco, política, experiencia.

Analisarei neste artigo a prosa ficcional de Severo Sarduy (1937-1993), constituída pelos romances Gestos (1963), De donde son los cantantes (1967), Cobra (1972), Maitreya (1978), Colibrí (1984), Cocuyo (1990) e Pájaros de la Playa (1993). Nestas análises, pretendo me contrapor à interpretação de críticos que leem a linguagem neobarroca sarduyana como a manifestação de uma "utopia da linguagem", que opóe o esbanjamento significante à "lógica economicista do capitalismo", aproximando-a assim a uma parcela de criadores e críticos da pós-modernidade capazes de resistir ao efeito de inércia gerado pela queda dos Grandes Relatos, principalmente a partir dos anos 1960. Vejam-se, a título de exemplo, dois fragmentos do ensaio "A Literatura Neobarroca ante a Crise do Moderno (sobre Severo Sarduy)", de Irlemar Chiampi:

Mais evidente ainda para essa linha de explicação do barroquismo como um exercício do esbanjamento que nega a lógica economicista do capitalismo, é o puro simulacro do travesti, tema que os romances sarduyanos exploram bastante (CHIAMPI, 1998: 33).

Preside, é claro, uma utopia da linguagem na síntese imaginativa que Sarduy constrói para projetar o barroco histórico na atualidade pós-utópica, ou seja, aquela que deverá regenerar-se de algum modo depois do colapso dos Grandes Relatos (CHIAMPI, 1998: 34).

Essa interpretação demasiadamente "antiburguesa" da produção ficcional sarduyana não combina com a perspectiva crítica - e aberta a variaçôes ao longo do tempo - do autor exilado em Paris em relação ao processo da Revolução Cubana, tampouco se coaduna ao deslumbramento de seus narradores e personagens diante da abundância imagética e arquitetônica, não apenas barroca mas também moderna. ${ }^{1}$ Pode-se dizer, sim, que Sarduy

\footnotetext{
${ }^{1}$ Gostaria de chamar a atenção para a seguinte passagem, provavelmente descartada de De donde son los cantantes e publicada por Sarduy em seu ensaio Escrito sobre un cuerpo: "Un crítico 'progresista': - El escritor francocubano Severo Sarduy, encerrado en las filigranas de su pensamiento bizantino, liberado del devenir histórico y convertido, por decirlo así, en una entelequia literaria, es víctima de las frías abstracciones de su torre de marfil, pues en este escamoteo prodigioso apenas se alude a la realidad. Si algo se refleja en Paradiso es una denuncia feroz de la corrupción de la sociedad de consumo, una crítica acérrima del sistema de la oferta y la demanda. ¿Hasta cuándo seguirá dedicado a perseguir esas síntesis y metáforas? ; Vamos, hombre! ¿Qué frivolidad! ¡Qué decadencia?’ (SARDUY, 1999: 1177-1178). Nela, o escritor parodia, justamente, as interpretaçôes da
} 
era contra a burocratização da vida burguesa e não contra o luxo e as diversas potencialidades eróticas advindas da relação entre dinheiro, poder e mercadoria, próprias do capitalismo. Há, na sua obra, um forte viés de contestação, percebido de maneira clara desde a publicação de De donde son los cantantes, quanto ao posicionamento político da esquerda latino-americana - visível em alguns escritores do Boom -, que unifica as noçóes de comunismo e identidade nacional, exotizando e essencializando, ao mesmo tempo, os mitos da tropicalidade e da comunidade rural contra o imperialismo capitalista neoliberal. ${ }^{2}$

É preciso ter atenção porém para, nesse intento de fugir à interpretação de cunho sociológico, não se cair no erro de tentar individualizar e valorizar a autenticidade de uma voz narrativa em movimento de dispersão constante, como a de Severo Sarduy. Mesmo François Wahl, em Severo de la Rue Jacob, ao fazer uma longa e interessante análise da obra sarduyana, entrelaçando-a à trajetória biográfica do escritor, avalia este movimento de dispersão como uma "generosidade" inventiva que singularizaria o estilo do autor, afirmando, por exemplo, que "Esse estilo é Severo. (...) Generosidade do gasto inventivo e generosidade do olhar caloroso que ele carrega. Temos aqui o que define o grão da voz de um autor" (WAHL, 1999: 1458. tradução livre).

A partir dessas consideraçóes, farei a seguir uma análise de como a questão política, presente na produção ficcional de Sarduy, constitui uma forma de dissidência em relação aos paradigmas cultivados pelos intelectuais e artistas de esquerda considerados, por um lado, "protagonistas" da resistência partidária, e por outro, "expoentes" das mais radicais experimentaçóes com a linguagem literária, durante os anos 1960-1990. Isso faz com que se problematize a própria inserçáo de Sarduy seja no cânone da literatura latinoamericana de sua época, seja no contexto do grupo da revista Tel Quel, ao qual ele se aproximou através de Phillippe Sollers e Wahl. Por isso, enfatizarei aqui procedimentos narrativos e figuras metafóricas que evidenciam a "dificuldade de narrar" desse escritor, seus obstáculos para transformar a experiência em ficção. Tal dificuldade é fruto, pois, não da excepcionalidade de uma voz criativa "à frente de seu tempo", mas de uma crise de valores ideológicos e estéticos experienciada por um artista homossexual cubano exilado na França, em meio a divergentes opinióes e perspectivas críticas em câmbio acelerado,

obra lezamiana e do neobarroco cubano, em geral, que, por desconsiderarem a potencialidade crítica do jogo (in)formal realizado a partir do campo superficial do significante, almejam, a todo custo, encontrar vieses de vinculação dessa produção estética com o dogmatismo político de extração marxista.

${ }^{2}$ Concordo, assim, com a sucinta análise da posiçãoo ocupada por Sarduy no cenário artístico francês dos anos 1970, feita por Emir Rodríguez Monegal na introdução a uma entrevista que o escritor cubano lhe concede: "Há em sua adesão a certas correntes literárias, críticas e plásticas de hoje um fervor intenso. Suas opinióes não são sempre ortodoxas. Porém, não há nenhum esforço nele pour épater le bourgeois" (RODRÍGUEZ MONEGAL, 1999: 1795. tradução livre). 
leitor-articulador de tradiçóes literárias e culturais europeias e não-europeias.

Política e dissidência

Os romances de Severo Sarduy não se situam necessariamente em Cuba. Alguns deles apresentam explícita ou implicitamente indícios de que o cenário da narrativa é a Havana do último ano da ditadura de Batista, época de agitaçáo oposicionista e revolucionária estudantil (Gestos), ou o período republicano da ilha, de onde o autor retira elementos para empreender uma leitura das superposiçóes culturais das culturas espanhola, africana e chinesa, que formariam, segundo ele, o hibridismo identitário cubano (De donde son los cantantes). ${ }^{3}$ Outros estão situados em ambientes indefinidos, embora contenham características de possíveis cenários caribenhos ou sul-americanos (Colibrí, Cocuyo, Pájaros de la playa). Outros ainda configuram o espaço narrativo por meio do deslocamento, nem sempre linear e claramente definido, das personagens por cidades e paisagens diversas - percurso este que vai do Oriente para o Ocidente (Cobra) ou do Ocidente para o Oriente (Maitreya).

Em cada uma dessas formas de compor o espaço narrativo, é possível vislumbrar diferentes meios encontrados por Sarduy para trazer à baila a maneira como a comunidade vivencia e problematiza questóes que, muitas vezes, são colocadas de modo maniqueísta na esfera do político, principalmente dentro de certa pespectiva do marxismo utópico. Em Gestos, por exemplo, a referência direta a Cuba é feita em uma prosa narrativa homóloga, segundo seu próprio autor, ao movimento plástico da action painting norte-americana. ${ }^{4} \mathrm{Com}$ isso, sua linguagem ganha aí grande independência em relação ao ponto de vista narrativo. Na verdade, a multiplicidade dos gestos das personagens, todas elas planas e imiscuídas à multidão que se agita devido às primeiras bombas e notícias dos ataques revolucionários, faz com que o espaço e a ação sejam o resultado de um movimento contínuo e quase sempre caótico. É importante assinalar o interesse de Sarduy pelo alheamento da população em relação aos acontecimentos políticos, de modo que os gritos dos muchachos que vendem os jornais pelas ruas representam a maneira desconexa como as informaçóes

\footnotetext{
${ }^{3}$ É importante ressaltar que Fernando Ortiz, no ensaio "Del fenómeno de la transculturación y de su importancia en Cuba" (1963), não enfatiza a presença da cultura chinesa no processo de transformaçóes (trans)culturais que resultou na identidade cubana. Em lugar disso, esse antropólogo recupera resquícios históricos das populaçôes indígenas que habitaram a ilha. Neste ponto, os autores divergem, pois para Sarduy não há heranças significativas da presença indígena que comprovasse sua importância dentro de uma tentativa de descrição cultural do país.

${ }^{4}$ Ao falar sobre Gestos, em entrevista a Emir Rodríguez Monegal, em 1977, Sarduy afirmará o seguinte: “(...) eu escapei da retórica do Nouveau roman. Em certo sentido, eu caí em algumas armadilhas. Contudo, trata-se, aplicando uma comparação plástica como disse, da influência de determinado tipo de Action painting à Franz Kline" (RODRÍGUEZ MONEGAL, 1999: 1798. traduçáo livre).
} 
chegavam às pessoas - "Prensa libre país prensa libre tiempo en Cuba alerta ataja prensa libre prensa libre” (SARDUY, 1999: 289) se aproxima à oralidade através da justaposição de fragmentos incompletos de enunciados que demonstram interesses múltiplos dos leitores, tanto por política quanto por meteorologia, em que a repetição, quase esvaziada, da expressão prensa libre vem acompanhada por sinais de silenciamento (ataja). Essa imagem do alheamento comparece também ao final do romance em uma passagem em que o autor descreve o comício de um candidato populista, arquétipo dos velhos caudilhos latino-americanos, cujo gestual continua reconhecível mesmo após o golpe político aludido sempre de maneira indireta pelo olor a pólvora que ainda se sente na cidade:

Ya los papeles y la niebla blanca caen sobre las cabezas. El avión se aleja. El candidato da un golpe con el puño cerrado sobre la baranda de la tribuna. La plataforma cruje. Abajo la serpiente da un salto, se desenrosca, cabecea, se anuda otra vez, vuelve a dormirse (SARDUY, 1999: 322).

Essa imagem animal que surge na citação de Gestos repete-se em $D e$ donde son los cantantes e indicia a crítica burlesca de Sarduy ao que ele chamou, neste romance, de ciclo zoofágico da política latino-americana (pré- e pósRevolução): "El Presidente, insultado, como alma que lleva el diablo, llama a la serpiente, que es el primer ministro. El reptil duerme, pero el primer magistrado lo despierta con insultos” (p. 373). Como já apontou o crítico Roberto González Echevarría, no ensaio "Plumas, sí: De donde son los cantantes y Cuba", a palavra Cuba não é pronunciada nem uma só vez em De donde son los cantantes, no entanto, o romance contém inúmeras alusóes à época em que a ilha servia de paraíso sexual para os norte-americanos - "Con la noche, cae ella del dólar al peso, de la cama al catre, del whisky al café con leche, del yes al sil Paradas en una esquina, en plena oferta" (p. 345) -; à problemática da negritude na América Hispânica, encenada na história através do desejo de serem brancas de suas personagens ${ }^{6}$ - "No es de esa agua la que quiero. Agua oxigenada: ¡seremos rubias!/ (...) ;Seremos blancas!l (...) ;Seremos pálidas! (p. 368) -; e às figuras paradoxalmente canonizadas de seus mártires "de carne e osso" - ora parecendo ser a encenação de um asmático Che, "Un ataque de tos Le rompió

\footnotetext{
${ }^{5}$ Como todos os fragmentos dos textos de Severo Sarduy serão extraídos de algum dos dois tomos de sua Obra Completa, publicada pela Colección Archivos (1999), doravante serão citadas entre parênteses apenas as páginas - e quando necessário o nome da obra - onde podem ser encontrados esses excertos. Além disso, as citaçóes literárias extraídas dos romances de Sarduy - objeto de análise deste artigo - serão mantidas em espanhol, sua língua original.

${ }^{6}$ Essa questão é apontada por Sarduy também em Gestos através de detalhes do comportamento de seus personagens, como, por exemplo, a reproduçáo do modo de falar das elites: "Los negros de La Habana cantan. Cucharas, sartenes. El nuevo ritmo. Ella lo sigue con los dedos, sobre la maleta. (...)/ Una mujer llama pronunciando las eses" (SARDUY, 1999: 325).
} 
los bronquios" (p. 419), ora a de um aristocrático e erotizado Fidel7, "Era rubio. Estaba desnudo. Con un pañuelo blanco. Volvía a gritar. ‘Azúcar!’ - Le gritaban. Reía. Llevaba pulseras de oro. Menos brillantes que sus ojos” (p. 421).

O processo de carnavalização (cf. BAKHTIN, 1999) das imagens mitificadas dos heróis da Revolução (que aqui podem dançar nus, gritando ¡Azúcar!) corresponde simultaneamente ao afastamento crítico do narrador em relação aos mitos da nacionalidade cubana. É preciso ressaltar que, em De donde son los cantantes, assim como em outros romances de Sarduy, ocorre a fragmentaçáo do ponto de vista da narrativa, a ponto de "Narrador Uno" e "Narrador Dos" discutirem entre si no meio da história. Além disso, as personagens podem, abruptamente, interromper o desenvolvimento do enredo para admoestar o narrador em $1^{\text {a }}$ pessoa, que seria aí uma referência irônica ao próprio autor: "Auxilio: Vamos, joven, no sea tan cubano. (Y llamando) Socorro, Socorro, oye lo que dice este indigena (soy yo)" (p. 396). Note-se que, no caso de Cuba, segundo Sarduy, ser indígena é ser o estranho, o menos aproximado aos substratos da "cubanidade" - se é que é possível utilizar este termo. Contudo, o narrador "indígena" é aí o mais "vergonhosamente" cubano diante de suas personagens mestiças que sonham enriquecer e europeizar-se. ${ }^{8}$ Tendo em vista esse jogo de problematizaçóes da identidade, concordo com a análise de De donde son los cantantes - título que se mantém no ambíguo limiar entre a pergunta e a afirmação - feita por González Echevarría, para quem, em última análise, essa é uma obra "sobre a impossibilidade de ser, e de ser de ou em algum lugar” (GONZÁLEZ ECHEVARRÍA, 1999: 1591).

Em romances em que o elemento espacial não é bem localizado, a referência indireta a Cuba é feita ora através de fatores atmosféricos “'Esto es tiempo de ciclón?" (Cocuyo, p. 804) -, ora por meio da presença de personagens cubanas na narrativa, através das quais são apontadas imagens desmistificadas que o socialismo centro-americano possui, principalmente, fora da América Latina. Ao falar, por exemplo, sobre Caimán, "el herborista cubano" que freqeenta a clínica onde se concentram as açóes de Pájaros de

\footnotetext{
${ }^{7}$ Sarduy destacou mais de uma vez em sua obra que a origem branca e aristocrática da família Castro lhe suscitava desconfianças em relação ao espírito revolucionário advindo dos filhos da elite criolla cubana. Em um trecho de "Severo Sarduy (1937...)", um dos seus primeiros textos autobiográficos, descreve Fidel da seguinte forma: "Entrada de Castro em Havana. (...) Era Branco e loiro. Quetzalcoalt de regresso" (SARDUY, 1999: 7, traduçấo livre).

${ }^{8}$ Embora o mais simples para os cubanos desde aquela época fosse a americanizaçáo, almeja-se aí mimetizar os mitos europeus legados pela tradição colonial por meio das leituras literárias. Veja-se a seguinte passagem em que o narrador repreende as atitudes pernósticas de Dolores Rondón, paródicas reproduçốes do gestual colonizador em uma personagem mulata: "Narrador Dos (compungido): (...) Dolores ha llegado a su barroco. (...) Las lecturas le han hecho mucho daño. La han enloquecido. Está bien que aprendiera inglés, que lo habla, entre paréntesis, como una haitiana; está bien que pidiera perfumes y flores congeladas a Miami, pero los clásicos cubanos han sido más fuertes que todo. Qué indigestión. Alli está, haciéndose abanicar por dos negras obesas a la salida de un baño de ron. Igual que la 'Condesa de Berlín', dice. ;Válganos!' (SARDUY, 1999: 371).
} 
la playa, o narrador afirma: "Rechazado como un objeto extraño por el cuerpo médico del hospicio, 'un utopista empedernido, o un delirante benigno como todos los de su pais', Caimán era tolerado, sin embargo, como visitante prolongado o residente de paso" (p. 958).

Outra maneira de se perceber a relevância da produção ficcional de Sarduy para uma reflexão sobre a Revolução são as menções diretas ou indiretas, presentes nela, a questóes sociais que caracterizam a vida em Cuba. Em Colibrí, a título de exemplo, verifica-se uma crítica de Sarduy em relação à distribuição, muitas vezes autoritária, dos postos de trabalho no regime socialista:

La crisis de la pugilística, espejo reductor de la crisis general, habia confinado a los nerviosos gimnastas imberbes en el parámetro de lavaplatos por substitución; no podian abandonar esa clausura detergente hasta que las armas ya engrasadas, que la necesidad erguia, de los uiltimos cazadores - los menos aguerridos, claro está-, dieran alcance a las ballenas más recalcitrantes, las más apegadas a los petrodólares y a la pelea (Colibri: 698).

Logo em seguida, em nota de rodapé, Sarduy esclarece ao leitor nãocubano o que significa parámetro no jargão trabalhista revolucionário:

Los que, aún aptos para ocupar los cargos más encumbrados, caen en el "diversionismo ideológico", o en su variante más perversa, el uranismo, se ven parametrados de la noche a la mañana, a la limpieza de letrinas y cloacas, o a la suplencia de zacatecas integrados, cuando azota, obra del anófeles apapipio 9 , el dengue viral (Colibrí: 698).

Note-se, pois, que Sarduy concentra sua atenção no fato de a homossexualidade (el uranismo) ser considerada em Cuba a variante "mais perversa” da dissidência ideológica. É importante perceber, com isso, a utilização que o autor faz dos signos relacionados aos universos feminino e homoerótico como forma de crítica irônica à performance de masculinidade vinculada à valorização da coragem dos guerrilheiros. Em De donde son los cantantes, as imagens fetichizadas do avanço dos filhos da elite branca para implantar o socialismo na ilha despertam a atenção popular: "- Vamos santiagueros, ¿quién es más macho que éste, quién es más blanco?” (SARDUY, 1999: 405). Já em Cobra, gostaria de ressaltar o endereçamento irônico aos leitores dos romances, apenas no feminino, e a referência satirizante ao machismo dos líderes da Revolução Cubana:

\footnotetext{
${ }^{9}$ Apapipio - gíria utilizada para designar informantes do governo.
} 
Estimadas lectoras:

sé que a estas alturas no os cabe la menor duda sobre la identidad del personaje alli desmesurado: claro, era Mei Lan Fang. Aparecía el octogenario impersonator de la Ópera de Pekin en su caracterización de dama joven - la coronoba una cofia de cascabeles - recibiendo un ramo de flores, la piña y la caja de tabaco del viril presidente de una delegación cubana (p. 430).

Nesse sentido, não seria equivocado afirmar que o orientalismo, cuja presença se nota preponderantemente nos romances em que a ação narrativa se desvela em concomitância ao movimento de viagem das suas personagens principais, funciona como forma de desarticulação dos modelos ocidentais de gênero e como burla à virilidade latina. Veja-se, em outra passagem desse mesmo romance, que as marcas de feminilidade, como as unhas extremamente afiladas, transformam-se em instrumentos capazes de ferir: “(...) las manos, cargadas de sortijas, terminan en uñas tan afiladas que las puntas de sus dedos parecen agujas" (p. 463). Podemos encontrar ainda, no processo de encenação de paisagens estrangeiras dentro da prosa ficcional sarduyana, referências a arquétipos da cultura gay dos EUA - leather, gay liberation, SM (cf. Cobra, p. 504). Sarduy - em um gesto que podemos aproximar à crítica empreendida pelo trabalho antropológico do argentino Néstor Perlongher, em $O$ negócio do michê (1987) - satiriza o comportamento da gay community norte-americana: "Nos masturbamos: TIGRE y TUNDRA; ESCORPIÓN y yo. Cada uno terminaba solo. Nadie toca la leche de otro. No nos miramos" (Cobra, p. 533). Essa citação, por exemplo, metaforiza uma época anterior à AIDS, mas já prenhe de individualismo. Pertencer à comunidade parece ser aí apenas circular pelos mesmos lugares, transar com desconhecidos, sem a necessidade de estabelecer qualquer diálogo com o outro. Desse modo, em Cobra, é possível o leitor se deparar com a seguinte asseveração - hoje já um tanto clichê, mas que caracterizava bem a cultura jovem dos anos 1970 - de que "La barbarie se llama Occidente" (p. 542).

Todavia, o caminho contrário desse percurso narrativo viajante também pode ser encontrado em Sarduy. Maitreya, seu livro considerado, a princípio, mais orientalista, configura a inversão do ponto de vista narrativo em direção ao Oriente, carregada pela erotização das paisagens, da arquitetura religiosa e da compleição física árabe masculina:

El chofer: rojo, duro también, sin vetas (...). Puños cerrados, brazos rígidos. Mirando fijo el nombre ardiente, como si las letras lo llamaran. Entró en erección. No sabian ya, los reunidos bajo la bóveda, qué milagro loar más, si la incandescencia de los arabescos o la túrgida musculatura que latía - lo único móvil en aquel museo de cera - tocando en su diástole, con el nudo proverbial, el vientre (p. 679). 
Essa pulsão erótica, que metonimicamente atravessa os arabescos das mesquitas e os corpos dos seus frequentadores, serve, é claro, mais uma vez de ironia em relação aos totalitarismos falocêntricos, como o do Islá, cuja expansão paralela ao crescimento do petrodólar, havia desencadeado, nesses países, "una arrafatada mania de verlo todo en grande" (p. 669).

\section{Impertinências}

Severo Sarduy ocupava um lugar oblíquo em relação às tendências políticas protagônicas da esquerda de sua época. Essa falta de conexão em relação à performatividade e à discursividade políticas, como se viu anteriormente, conduzia sua ficção a caminhos alternativos, por alguns valorizados como originalidade criativa terceiro-mundista, por outros hostilizados por se afastar do empenho crítico da juventude marxista contra o capitalismo dominante. Seguramente, o autor de Nueva inestabilidad não se enquadrava na retórica intelectual que acompanhou a recepçáo bem-sucedida dos escritores latinoamericanos nos EUA e na Europa, não pelo seu (pseudo-)orientalismo, presente também em autores como Octavio Paz e Julio Cortázar, mas por sua confessa dificuldade de dar forma narrativa à memória e à experiência do contemporâneo. Isso me leva a crer que o olhar sagital lançado em combate ao machismo revolucionário, sobretudo, seja em Sarduy inexoravelmente tensionado pela ausência de paradigmas genéricos - falo aqui, decerto, na duplicidade da ideia de gênero, sexual e textual:

Entre sus figuras constantes, a lo largo de los siglos, la Retórica ha catalogado la excusatio propter infirmitatem, esa confesión de modestia, de incapacidad ante el tema a tratar, que debe preceder todo discurso. No la utilizo aqui (aunque esta denegación sea una de sus formas): la impertinencia de las páginas que preceden la declaran por mi, de sobra (p. 423).

A partir dessa recuperação da modéstia retórica, extraída de $D e$ donde son los cantantes, Sarduy indicia uma vinculação metonímica entre impertinência e sobra. Impertinência do inoperante (cf. NANCY, 2000). O excesso da oferta passiva de signos, imagens, joias e plumas, torna-se, em outros textos, uma forma de resistência indecodificável para o vocabulário político: "Se dieron finalmente, las dos, a la resistencia pasiva. Practicaban la no intervención" (Cobra, p. 447). E talvez esteja nessa inércia o poder de diferenciação da fusão arte-comunidade-política na literatura latino-americana. Essa linha de análise vem sendo produtivamente investigada por alguns estudiosos. Leia-se a título de exemplo o seguinte trecho de Joca Wolff, em Telquelismos latinoamericanos: 
Como disse Panesi [a propósito de César Aira], "a história americana é inconcebível sem o jogo pelo qual o americano vê os outros olharem a América”. O impasse ocidental é naturalmente parte da agenda dos telquelianos latinoamericanos cujas soluçôes, no entanto, costumam ser "bárbaras e nossas", segundo o Manifesto Antropófago, de Oswald de Andrade. Ao contrário do dependentismo e sua ideologia, a das ideias transplantadas e "fora de lugar" (Roberto Schwarz), é preferível ler - afirma Antelo - "uma modernidade dos pobres e dependentes que redefine a modernidade como universalidade a partir de uma atividade de inércia traduzida como energia diferencial e transgressiva" (WOLFF, 2009: 29 - tradução livre).

Essa visão inverte, pois, a concepção tradicional que se tem da ideia de inércia. Sarduy avalia o vazio como um espaço produtivo, aberto à criação a-significante e figural (cf. LYOTARD, 1971), opondo-se à lógica ocidental, o que não significa necessariamente crítica à economia capitalista. Isso quer dizer, portanto, que o esvaziamento do sentido não é uma atribuição única e exclusiva dos elementos orientais. Não à toa, em vários romances sarduyanos, a narrativa promove a articulação entre índices da cultura moderna industrial e budismo - "Un lama engurruñado y feo, el manto mal colgado sobre un pull-over" (Maitreya, p. 587 - grifos meus) -, ou desde outra perspectiva, capta tal articulação em cenas tipicamente hispano-americanas: "Las viejas estaban sentadas en dos esteras enrolladas, a ambos lados de la cabeza, de perfil, mirando al vacio, tejedoras nostálgicas. / Tomándose un chocolate con churros" (Maitreya, p. 621 - grifos meus). A atitude contemplativa liga-se aí à questão da repetição, muitas vezes destacada pelo romancista como uma maneira de alcançar o esvaziamento do significante: "los rozaban con la mano y repetian, aunque pensando en otra cosa, las fórmulas consabidas hasta que no significaran nada, hasta el vaciamiento" (Maitreya, p. 625).

Justamente por isso, o entendimento de que toda ausência se torna "un principio y un medio de abstracción y de movimiento, ya que propone un continente, una forma a la posibilidad de un contenido" (p. 961), não pode ser vinculado apenas a Maitreya mas também a outros romances do autor, como Pájaros de la playa, narrativa que enfoca uma questão extremamente importante para o mundo ocidental, a saber, a descoberta e o avanço rápido da epidemia da AIDS, a partir de 1981. Nela, o personagem Caimán, que representa lo cubano dentro do mosaico de caracteres que compóe a trama textual, é responsável pela reflexão trazida como contraponto à perspectiva melancólica que acompanha a doença das demais personagens, e também do próprio autor do texto: "Todo lo que está lleno es inerte. Lo vacío es una condición esencial del movimiento y de la vida” (p. 961). A propósito dessa relação entre cubanidade e vazio, gostaria de retormar aqui a interessante leitura, feita por González Echevarría, da sentença que inicia De donde son 
los cantantes: "Plumas, sì". O autor nos recorda que, na variedade centroamericana da Língua Espanhola, as palavras plumas e pájaros podem ser utilizadas como gírias para homossexual masculino. Desse modo, haveria aí uma vontade de afirmação homoerótica que não se reduziria a uma identidade plena, mas representaria antes uma alegria diante do vazio, humor contra a ameaça do nada, desejo de contrapor pequenas vitórias ao caos e à negação (cf. GONZÁLEZ ECHEVARRÍA, 1999: 1604).

Se a ausência pode ser considerada uma força motriz da escrita literária sarduyana, é possível refletir que seu interesse pelos ritos católicos, hinduístas e yorubas, quase indistintamente, não significa adesão acrítica e/ou esotérica a qualquer uma dessas religióes, mas na verdade uma vontade de explorar novas posibilidades de (des)figuração da realidade. Não é preciso dizer que o elemento místico, qualquer que seja, é dotado desta potencialidade de contaminação do real, de modo que a naturalização do olhar do adepto ao culto reliogioso faz com que ele náo perceba o irrealismo da sua própria fé. Esse é um aspecto interessante para a prosa de Sarduy, que constrói seus universos narrativos a partir da plasticidade onírica e da ritualidade atávica dos ambientes religiosos, embora sua escrita rejeite qualquer forma de transcendência inequívoca. Nela, o esvaziamento da vida e do sujeito torna-se passaporte para a artificialidade e para o transitório. Não à toa, em Maitreya, podemos encontrar uma passagem que comprova esse sentido de impermanência de todas as crenças na obra sarduyana: "Adoptaron otros dioses, águilas. Mimaron ritos hasta la idiotez o el hastio. Para demostrar la impermanencia y vacuidad de todo" (p. 689).

Em Severo de la Rue Jacob, François Wahl (In: SARDUY, 1999: 1475) já havia comentado que o interesse de Sarduy pelo hinduísmo e pelo budismo era apenas intelectual e estético - mote para o apagamento de si dentro da escrita literária -, tentando evitar assim interpretaçóes demasiado orientalistas da obra desse autor. O próprio Sarduy, inclusive, já havia explicitado sua postura crítica como escritor: "Não seguir nenhum guia, náo adotar os preceitos de nenhuma religião, nem seita, descartar toda autoridade espiritual ou moral" (SARDUY apud GUERRERO, 1999: 1702, tradução livre). Isso pode ser percebido, por exemplo, através da mudança abrupta de regimes de credo em sua obra - vide a superposição entre o budismo, a santería e o catolicismo em De donde son los cantantes. E se Sarduy, antes de morrer, dedicava diversas horas de seu dia a reler a obra de San Juan de la Cruz, é porque apreciava, conforme afirma em "El estampido de la vacuidad", o misticismo não ingênuo desse autor, que entende "o ser da divinidade" como "precisamente o não-manifesto, o que náo tem acesso ao mundo dos fenômenos, nem à percepçáo" (p. 106 - tradução livre). Sendo assim, o diálogo com o místico através da escrita literária também esbarrará, inevitavelmente, com a própria impertinência da materialidade sensível da linguagem verbal em dar forma àquilo que não é 
da ordem da percepção.

É paradigmático, nesse sentido, encontrarmos na prosa ficcional de Sarduy algumas passagens que relacionam conceitos do domínio do discurso religioso à noção de "simulaçáo", desenvolvida por ele em um estudo publicado em 1982. Leiam-se, como exemplos, os trechos a seguir: "Dios es simulación. El que más finja es su elegido" (Colibrí, p. 732); "Mi espiritu ya no habita mi cuerpol Lo que ahora come, duerme, habla y excreta en medio de los otros es una pura simulación" (Pájaros de la playa, p. 921). Para o autor, a simulação configura uma intensidade para além dos binarismos que, semanticamente, regem a lógica de produção dos sentidos. Em um dos trechos narrativos que entremeiam o ensaio sarduyano, afirma-se o seguinte:

Para que tudo signifique é preciso aceitar que me habita, não a dualidade, mas uma intensidade de simulação que constitui seu próprio fim, para além do que imita: o que se simula? A simulação.

E agora, em meio a almofadas rubendarianas e jogos de cortina, com fundo de biombos e valsas - entre passarinhos e frangos -, só eu reino, atravessado pela simulação, imantado pela reverberaçáo de uma aparência, esvaziado pelo estremecimento do riso: anulado, ausente (La simulación, p. 1265-1266, tradução livre).

Essa vontade de ultrapassar as oposiçóes rígidas e o desenvolvimento em sentido único tem a ver com a concepçáo de vazio para a cultura chinesa. ${ }^{10}$ Outrossim, é preciso chamar a atenção, como se pode ver na citação acima, para o fato de que tanto a noção de simulação quanto a aproximação de Sarduy à prática do zen náo correspondem a um abandono do potencial imagético da linguagem neobarroca: excessiva, detalhista, impertinente...

Passando agora a outros registros da simulação em Sarduy, vê-se, por exemplo, que a encenação do castigo sadomasoquista é, ao mesmo tempo, responsável por incontroláveis proliferaçóes sígnicas, investimentos desejantes sobre objetos visíveis e anulação dos sujeitos envolvidos nessa prática sexual: "O escravo (...) não é mais do que titubeio e cegueira: o orifício de sua boca é só recipiente ou devorador, lugar de descarga ou de sucção. Nunca de palavra: (...) the é proibido falar" (La simulación, p. 1338 - tradução livre). Retomando sua produção ficcional, nota-se que, em Colibrí, tal intensidade de simulação recobre o erótico, logrando paralisar a cena narrativa e fazer o narrador reduzir o protagonista a uma posição coadjuvante: "El olvidado protagonista de estas páginas contemplaba aquel afocante full-contact, boquiabierto y con el brazo derecho extendido - desnudo ya lo estaba" (p. 741). Apesar dessas

\footnotetext{
${ }^{10}$ Vide citação de Vide et plein, le langage pictural chinois, de François Cheng, feita por Sarduy no seu ensaio La simulación (CHENG apud SARDUY, 1999: 1330).
} 
referências à tensão entre sexo e violência, na verdade, pode-se dizer que a atitude de Sarduy diante da imagem, como a de Rauschenberg, não é a de iconoclastia experimentalista ou de agressão frontal, "mas a de desconfiança, de ironia: é um inimigo invisível, noturno" (La simulación, p. 1329 - tradução livre). Isso demonstra que o impulso principal da produção sarduyana não é o enfrentamento aguerrido, tampouco o apego a qualquer espécie de transcendência ou metafísica, e sim o afá de trazer a linguagem literária para um terreno de discussão e crise dos próprios códigos que a constituem.

É preciso dialetizar a ideia de "crise" utilizada aqui, visto que, para Sarduy, a crise, ou melhor, as crises sucessivas encetadas por sua prosa narrativa representam a vontade de obter estágios de figuraçáo/simulação localizados no interior desses movimentos de desestabilização conceitual, onde estão implicados consecutivamente os deslocamentos dos regimes de signos e os códigos culturais colocados em tensão. Por isso, em Cocuyo, o narrador chega a valorizar a noção de tranquilidade, mostrando, através de uma outra perspectiva, o modo como passividade e transgressáo fazem parte de um mesmo nó filosófico, afirmando que "Eso era, pues, la calma: un entreacto entre dos crisis, un pensamiento estable entre dos locuras" (p. 845); “(...) calma engorrosa, como la que sigue a la blasfemia. O a la suciedad del sexo” (p. 858). E não só o sexo é retomado aí como "dobradiça" entre esses momentos de instabilidade e estabilidade, a paz encontrada no êxtase religioso pode passar abruptamente à agitação demoníaca: "Se ha visto el caso (...) de monjas teresianas que, sin ser acróbatas, han pasado sin transición del éxtasis a la flexión compulsiva: babeando y con los ojos vidriosos se doblan hacia atrás... Llegan a pegar la cabeza a los talones" (p. 825). Tais imagens do movimento pendular que vai da letargia à aceleração extrema, aproveitadas como interessantes metáforas da própria escrita literária, comparecem ainda no romance por meio das noções de embriagamento e convulsão atmosférica: "lentitud de giros, torpes y enredada como el habla de un borracho. Todo podía explicarlo ese letargo que, debido a las perturbaciones magnéticas, se apodera de los cuerpos sensibles después del paso de un ciclón” (p. 820, grifos meus).

O interessante, em Cocuyo, é que seu personagem principal ocupa a posição de um "leitor" para quem a configuração da imagem narrativa parece frequentemente algo ininteligível/ininterpretável. Com isso, Sarduy explicita a questão pós-moderna que mais lhe interessa, qual seja, a relação entre o informe e a impugnação paródica da razão. Sua narrativa, cuja imagem central se desenvolve em meio a "retorcidos ayuntamientos guirnaldas de orquideas" (p. 893), cruzamentos de animais dissímiles e enxertos grotescos, sugere um desafio ao entendimento, apesar de sua natureza extremamente imagética. Essa vinculação entre o ler e o ver é também destacada por Gilles Deleuze como um processo de deslizamento constante, da forma e do conteúdo, típico do 
barroco. ${ }^{11}$ Isso prevalece também no romance seguinte, Pájaros de la playa, o último de Sarduy, onde o "pensar descosido" (p. 956), resultado da fadiga e da enfermidade, aponta mais uma vez a problematização da noção de vazio. Apesar de a ausência estar diversas vezes vinculada à morte em sua obra, tanto o esvaziamento da escrita quanto o abandono do ser - aberturas, como vimos, para a produção ficcional neobarroca - estâo submetidos a uma dupla dificuldade, a de escrever e de morrer: "Habría que escribir un breviario: De la dificultad de morir" (p. 968), o que nos remete ainda à importante filiação com a obra de José Lezama Lima, fartamente projetada e cultivada por Sarduy. Recorde-se, pois, o início de "Mitos e cansaço clássico", ensaio incluído em A expressão americana: "Somente o difícil é estimulante" (LEZAMA LIMA, 1988: 47). A partir daí, Lezama define a noção de dificuldade como

a forma em devir em que uma paisagem vai em direção a um sentido, uma interpretação ou uma simples hermenêutica, para ir depois em busca da sua reconstrução, que é o que marca definitivamente sua eficácia ou desuso, sua força ordenadora ou seu apagado eco (...). Eis aqui, pois, a dificuldade do sentido e da visão histórica (LEZAMA LIMA, 1988: 47).

O importante desta reflexão de Lezama é justamente o modo como ela insere a possibilidade de formação de uma visão histórica americana dentro da problemática do devir, da constância do movimento tradutório, imaginativo e transcultural, que faz da arte barroca do continente um interessante corpus para se vislumbrar essa difícil tensão com a hererogeneidade do material simbólico, vivenciada pelo homem americano no intento de configurar noções "próprias" para sua cultura. Dessa forma também entendemos a estética neobarroca sarduyana, na qual a "dificuldade de narrar" não deixa de ser fruto de um desejo simultâneo de apreensão e abandono do sentido, focalização e digressão impertinente, aproximação e repúdio em relação ao que se tenta erigir como cultura latino-americana.

\section{Referências bibliográficas}

BAKHTIN, Mikhail. A cultura popular na Idade Média e no Renascimento: o contexto de François Rabelais. São Paulo: Hucitec, 1999.

CHIAMPI, Irlemar. Barroco e modernidade. São Paulo: Perspectiva, 1998.

\footnotetext{
${ }^{11}$ Em $A$ dobra, Deleuze (1991: 60) afirma que "As combinaçōes de visível e legível constituem os 'emblemas' ou as alegorias caras ao Barroco. Somos sempre remetidos a um novo tipo de correspondência ou de expressão mútua, entr'expressāo, dobra conforme dobra."
} 
DELEUZE, Gilles. A dobra: Leibniz e o barroco. Campinas: Papirus, 1991.

GONZÁLEZ ECHEVARRÍA, Roberto. "Plumas, sí: De donde son los cantantes”. In: SARDUY, Severo. Obra Completa. ed. crítica de Gustavo Guerrero y François Wahl (Coords.). Madrid: ALLCA XX/Scipione Cultural, 1999: 1582-1604.

LEZAMA LIMA, José. A expressão americana. São Paulo: Brasiliense, 1988.

LYOTARD, Jean-François. Discours, figure. Paris: Klincksieck, 1971.

NANCY, Jean-Luc. La comunidad inoperante. Santiago de Chile: Arcis, 2000.

ORTIZ, Fernando. Contrapunteo cubano del tabaco y del azúcar. La Habana: Consejo Nacional de Cultura, 1963.

PERLONGHER, Néstor. O negócio do michê. São Paulo: Brasiliense, 1987.

RODRÍGUEZ MONEGAL, Emir. "Entrevista a Severo Sarduy”. In: SARDUY, Severo. Obra Completa. ed. crítica de Gustavo Guerrero y François Wahl (Coords.). Madrid: ALLCA XX/Scipione Cultural, 1999: 1795-1810.

SARDUY, Severo. Obra Completa. ed. crítica de Gustavo Guerrero y François Wahl (Coords.). Madrid: ALLCA XX/Scipione Cultural, 1999. 2 vol.

WAHL, François. “Severo de la rue Jacob”. In: SARDUY, Severo. Obra Completa. ed. crítica de Gustavo Guerrero y François Wahl (Coords.). Madrid: ALLCA XX/Scipione Cultural, 1999: 1447-1550.

WOLFF, Jorge. Telquelismos latinoamericanos: la teoría crítica francesa en el entre-lugar de los trópicos. Buenos Aires: Grumo, 2009.

Antonio Andrade. Professor da Universidade Federal do Rio de Janeiro. Coordenador do Programa de Pós-Graduação em Letras Neolatinas da UFRJ. Graduado em Letras Português-Espanhol, mestre e doutor em Letras pela Universidade Federal Fluminense. Líder do Laboratório de Ensino, Pesquisa e Extensão em Formação de Professores de Línguas (FORPROLI). Coordenador da área de Letras Espanhol do PIBID-UFRJ. Membro da Diretoria da Associação Brasileira de Hispanistas 2012 a 2014 e organizador do VIII Congresso Brasileiro de Hispanistas (2014). Vem atuando nos seguintes temas: literatura e política na contemporaneidade, neobarroco, comunidade, formação de professores de português/espanhol, análise do discurso, manifestações literárias/culturais e ensino de línguas.

E-mail: antonioandrade.ufrj@gmail.com

Recebido em: 15/09/2016

Aprovado em: 03/12/2016 